\title{
Efficacy of lower doses of aminopyralid + piroksysulam + florasulam (Lancet Plus 125 WG) applied with adjuvant in winter wheat
}

\author{
Ocena skuteczności działania obniżonych dawek mieszaniny \\ aminopyralid + piroksysulam + florasulam (Lancet Plus 125 WG) \\ z dodatkiem adiuwanta w pszenicy ozimej
}

Krystyna Miklaszewska, Roman Kierzek

\begin{abstract}
Summary
The aim of this study was to evaluate weed susceptibility to herbicides, applied at reduced doses in winter wheat. The herbicide Lancet Plus 125WG (aminopyralid + piroksysulam + florasulam) was used in a tank-mixture with the adjuvant Olstick $90 \mathrm{EC}$ at a dose of $1.0 \mathrm{l} / \mathrm{ha}$. The herbicide was applied at five doses: at the recommended dose, and at $75,62.5,50$ and $37.5 \%$ of the recommended dosage. Lancet Plus 125 WG at the dose of $0.2 \mathrm{~kg} / \mathrm{ha}$ was used as a standard. The experiments were conducted in randomized block design with four replications at the Experimental Station of the Institute of Plant Protection - National Research Institute in Winna Góra and on the private farm in Kluczewo Huby during two growing seasons (2010/2011 and 2012/2013). The tested herbicides were applied from the full tillering stage until first node stage of winter wheat (BBCH 25-31). During treatment the weed species were at a growth stage from 14 to 31 according to $\mathrm{BBCH}$ scale. The most common species of weeds were: Viola arvensis, Centaurea cyanus, Papaver rhoeas, Brassica napus, Matricaria inodora, Thlaspi arvense and Apera spica-venti. The results showed the possibility to reduce the herbicide doses at range of $25-50 \%$, while maintaining their high herbicidal effectiveness and good effect on the stability of grain yield.
\end{abstract}

Key words: winter wheat; weeds; reduced doses; herbicide; adjuvant; aminopyralid + piroksysulam + florasulam

\section{Streszczenie}

Celem badań była ocena wrażliwości chwastów występujących w uprawie pszenicy ozimej na obniżone dawki herbicydu Lancet Plus 125 WG (aminopyralid + piroksysulam + florasulam) stosowanego łącznie z adiuwantem Olstick 90 EC w dawce $1 \mathrm{l} /$ ha. Herbicyd aplikowano w pięciu dawkach: pełnej, rekomendowanej oraz w 75; 62,5; 50 oraz 37,5\% dawki zalecanej. Porównawczo zastosowano Lancet Plus 125 WG bez adiuwanta, w zalecanej dawce $0,2 \mathrm{~kg} / \mathrm{ha}$. Doświadczenia prowadzono przez dwa sezony wegetacyjne (2010/2011 i 2012/2013) na terenie Polowej Stacji Doświadczalnej Instytutu Ochrony Roślin - Państwowego Instytutu Badawczego w Winnej Górze oraz w prywatnym gospodarstwie Kluczewo Huby w układzie bloków losowanych w czterech powtórzeniach. Herbicydy aplikowano $w$ fazie od pełni krzewienia do początku fazy strzelania w źdźbło (BBCH 25-31). W momencie zabiegu chwasty znajdowały się w fazach BBCH od 14 do 31. Najczęściej występującymi gatunkami chwastów były: Viola arvensis, Centaurea cyanus, Papaver rhoeas, Brassica napus, Matricaria inodora, Thlaspi arvense oraz Apera spica-venti. Wyniki wskazują, że łączne stosowanie herbicydu Lancet Plus 125 WG z adiuwantem Olstic 90 EC pozwala na obniżenie dawki herbicydu w granicach 25-50\%, przy zachowaniu wysokiej skuteczności chwastobójczej oraz stabilnego plonowania pszenicy ozimej.

Słowa kluczowe: pszenica ozima; chwasty; obniżone dawki; herbicydy; adiuwant; aminopyralid + piroksysulam + florasulam

Instytut Ochrony Roślin - Państwowy Instytut Badawczy

Władysława Węgorka 20, 60-318 Poznań

K.Miklaszewska@iorpib.poznan.pl 


\section{Wstęp / Introduction}

We współczesnym rolnictwie stosowanie herbicydów w zbożach jest stałą praktyką (Banaszkiewicz 1993; Kraska 2007). Pszenica ozima ze względu na małą konkurencyjność spowodowaną krótkosłomymi, intensywnymi odmianami jest gatunkiem wrażliwym na zachwaszczenie (Wesołowski i Cierpiała 2010). W praktyce rolniczej, do tej pory najczęstszą metodą ochrony upraw przed zachwaszczeniem było stosowanie herbicydów (Haliniarz i Kapeluszny 2012; Miklaszewska i Kierzek 2013). Aplikowanie chemicznych środków ochrony roślin w dużych ilościach może skutkować negatywnym wpływem na środowisko, jak i samą roślinę uprawną (Domaradzki i Sadowski 2002; Krawczyk 2007; Miklaszewska i Kierzek 2013). Tendencją ostatnich lat $\mathrm{w}$ światowym rolnictwie jest ograniczanie dawek i liczby zabiegów herbicydowych (Domaradzki i Praczyk 2004; Wesołowski i Cierpiała 2010; Miklaszewska i Kierzek 2013). Prowadzi to do ograniczenia ryzyka zanieczyszczenia środowiska przez pozostałości substancji czynnych w produktach zbożowych oraz pozwala na zmniejszenie kosztów zabiegu (Domaradzki i Rola 2001; Kwiatkowski i Wesołowski 2011). Przez dodatek adiuwantów do cieczy użytkowej, dzięki poprawie absorpcji substancji czynnej oraz procesów retencji, można zmniejszyć dawkę substancji czynnej (Kierzek i Ratajkiewicz 2004; Kwiatkowski i Wesołowski 2011).

Celem badań była ocena wrażliwości chwastów występujących w uprawie pszenicy ozimej na obniżone dawki herbicydu Lancet Plus 125 WG stosowanego łącznie $\mathrm{z}$ adiuwantem Olstick 90 EC. W badaniach oceniano również wpływ zabiegów odchwaszczających na plon i elementy jego struktury.

\section{Materiały i metody / Materials and methods}

Trzy doświadczenia nad stosowaniem obniżonych dawek herbicydu wraz $\mathrm{z}$ adiuwantem $\mathrm{w}$ uprawie pszenicy ozimej prowadzono przez dwa sezony wegetacyjne (2010/2011 i 2012/2013). Założono je w układzie bloków losowanych w czterech powtórzeniach na terenie Polowej Stacji Doświadczalnej Instytutu Ochrony Roślin - Państwowego Instytutu Badawczego w Winnej Górze (w obu sezonach) oraz w gospodarstwie prywatnym Kluczewo Huby (w sezonie 2010/2011). Powierzchnia jednego poletka wynosiła $16,5 \mathrm{~m}^{2}$. Doświadczenia w Winnej Górze prowadzono na glebach brunatnych wytworzonych z piasków gliniastych mocnych, natomiast w Kluczewie Huby na glebie brunatnej wyługowanej wytworzonej z piasków gliniastych średnich, zaliczanych do III i IV klasy bonitacyjnej. Badania wykonano na dwóch odmianach pszenicy ozimej: Muszelka (2010/2011 - Winna Góra i Kluczewo Huby) oraz Legenda (2012/2013 - Winna Góra). Zastosowano standardowe nawożenie mineralne $\mathrm{N}(130 \mathrm{~kg} / \mathrm{ha})$, $\mathrm{P}(60 \mathrm{~kg} / \mathrm{ha}), \mathrm{K}(80 \mathrm{~kg} / \mathrm{ha})$ oraz wymaganą ochronę przeciwko szkodnikom i chorobom grzybowym.

Herbicyd Lancet Plus 125 WG stosowany w doświadczeniach to środek zawierający trzy substancje aktywne o uzupełniającym się sposobie działania. Są to: $25 \mathrm{~g} / \mathrm{kg}$ florasulamu, $50 \mathrm{~g} / \mathrm{kg}$ aminopyralidu i $50 \mathrm{~g} / \mathrm{kg}$ piroksysulamu. Związki te należą do grupy triazolpirymidyn. Lancet Plus 125 WG jest selektywnym herbicydem o działaniu systemicznym, pobieranym przez liście chwastów i szybko przemieszczanym w całej roślinie.

Badany herbicyd aplikowano w fazie od pełni krzewienia do początku fazy strzelania w źdźbło, tzn. w fazie BBCH 25-31. W chwili zabiegu chwasty znajdowały się w fazach BBCH od 14 do 31 . Zabiegi wykonano opryskiwaczem poletkowym przy użyciu rozpylaczy szczelinowych XR 11003 i ciśnieniu roboczym 0,15 MPa, dla ustalonej dawki cieczy użytkowej 200 1/ha.

Lancet Plus 125 WG stosowano w pięciu dawkach: zalecanej $(0,2 \mathrm{~kg} / \mathrm{ha})$ oraz obniżonej o $25 ; 37,5 ; 50$ i $62,5 \%$. Środek stosowano łącznie $\mathrm{z}$ adiuwantem Olstick 90 EC (estry metylowe wyższych kwasów tłuszczowych $-65 \%$, kwas oleinowy - 25\%) w dawce 1 1/ha. Obserwacje zwalczania chwastów przeprowadzono w okresie od 2 do 7 tygodni po wykonaniu zabiegu. Na obiekcie kontrolnym (bez zabiegu) za pomocą ramki o wymiarach $0,25 \times 1,0 \mathrm{~m}$ ustalono liczbę poszczególnych gatunków chwastów. Na każdym poletku w ocenie wizualnej, na podstawie liczebności i kondycji chwastów, oszacowano skuteczność działania herbicydu, którą wyrażono w procentach. Do wyznaczenia dawki efektywnej $\mathrm{ED}_{90}$, powodującej $90 \%$ zniszczenie poszczególnych gatunków chwastów zastosowano program komputerowy Polo Plus (Robertson i wsp. 2002), z wykorzystaniem profilu skuteczności chwastobójczej różnych dawek herbicydu Lancet Plus 125 WG. Po zbiorze ustalono wysokość plonu, masę tysiąca ziaren oraz gęstość ziarna w stanie zsypnym. Wyniki 2-letnich obserwacji uśredniono, a plon pszenicy ozimej poddano analizie statystycznej (test t-Studenta na poziomie 5\%).

\section{Wyniki i dyskusja / Results and discussion}

We wszystkich trzech doświadczeniach prowadzonych w ciągu dwóch sezonów wegetacyjnych najliczniej reprezentowanymi gatunkami chwastów były: Viola arvensis, Centaurea cyanus, Papaver rhoeas, Matricaria inodora, Thlaspi arvense, Galium aparine, Apera spica-venti i samosiewy rzepaku.

W momencie przeprowadzania zabiegów opryskiwania, które miały miejsce $\mathrm{w}$ drugiej połowie kwietnia większość gatunków nie przekroczyła fazy rozwojowej 20 według skali BBCH. Już pierwsza ocena zwalczania poszczególnych gatunków chwastów, przeprowadzona po około dwóch tygodniach od opryskiwania wykazała wysoką skuteczność stosowanych kombinacji zabiegowych. W trakcie kolejnych obserwacji stwierdzono, że efekt chwastobójczy zwiększał się. Dla trzech doświadczeń uśrednione wyniki skuteczności działania różnych dawek herbicydu Lancet Plus 125 WG stosowanego z adiuwanttem Olstick 90 EC podano w tabeli 1. (dane $\mathrm{z}$ ostatnich obserwacji wykonanych około 7 tygodni po zabiegu). Na podstawie uzyskanych danych można stwierdzić, że obniżanie dawki herbicydu do 75 ; 62,5 i 50\% nie Powoduje większych różnic $\mathrm{w}$ poziomie zwalczania chwastów w porównaniu do dawki zalecanej. Do uzyskania $90 \%$ $\left(E_{90}\right)$ skuteczności zwalczania wszystkich dominujących 
gatunków chwastów w pszenicy ozimej wystarczającymi okazały się niższe testowane dawki herbicydu Lancet Plus $125 \mathrm{WG}$ stosowanego łącznie $\mathrm{z}$ adiuwantem Olstick $90 \mathrm{EC}$ (poza dawka $0,75 \mathrm{~kg} / \mathrm{ha}$ ). Potwierdzone zostały rezultaty wcześniejszych badań dotyczących możliwości zastosowania adiuwantów w celu zwiększenia skuteczności chwastobójczej, jak i możliwości obniżenia dawek herbicydów (Domaradzki i Rola 2003; Domaradzki i Kieloch 2005; Praczyk i wsp. 2008; Miklaszewska i Kierzek 2013). Właściwości cieczy użytkowej, modyfikowane przez dodatek adiuwantów i stosowanie preparatów o różnych formach użytkowych mogą istotnie wpływać na ilość i rozkład depozytu na roślinach (Holloway i wsp. 2000). Ważnym jest także wybór właściwego adiuwanta do odpowiedniej formy użytkowej herbicydu, gdyż formulacja środka ochrony roślin $\mathrm{w}$ połączeniu $\mathrm{z}$ adiuwantem o specyficznych właściwościach fizyko-chemicznych może w różny sposób wpływać na działanie i zachowanie substancji czynnej na powierzchni roślin traktowanych (Kudsk 2008).

W badaniach nie stwierdzono znaczących różnic w skuteczności działania herbicydu Lancet Plus 125 WG stosowanego w dawce zalecanej, tj. $0,2 \mathrm{~kg} / \mathrm{ha}$ pojedynczo, jak i z dodatkiem adiuwanta. Obniżenie dawki herbicydu do 75 i $62,5 \%$ w stosunku do dawki zalecanej oraz zastosowanie go wraz z adiuwantem Olstick 90 EC pozwoliło uzyskać bardzo wysoki efekt chwastobójczy w stosunku do wszystkich występujących w doświadczeniu gatunków chwastów (94-100\%). W przypadku obniżenia dawki do 50\% skuteczność kształtowała się na poziomie od 89 do $94 \%$. Po zmniejszeniu dawki do $37,5 \%$ dawki zalecanej również uzyskano nadal dobre efekty chwastobójcze (83-92\%), co pozwoliło na skuteczne ograniczenie zachwaszczenia w pszenicy ozimej, bez znaczącego wpływu na dalszy wzrost i rozwój rośliny uprawnej. Otrzymane wyniki są zgodne z doniesieniami innych autorów, którzy wskazują na możliwość obniżania dawek herbicydów w zabiegach nalistnych o 25-50\%, przy zachowaniu wysokiej efektywności chwastobójczej i bez istotnego obniżenia plonowania zbóż (Domaradzki i Rola 2003; Talgre i wsp. 2004). Wyniki innych badań sugerują, że w niektórych latach stosowanie obniżonych dawek herbicydów wystarczająco zabezpiecza plantację przed zachwaszczeniem w porównaniu do stosowania pełnych zalecanych dawek w latach o niekorzystnym przebiegu wegetacji roślin i zróżnicowanych warunkach pogodowych (Bostrom i Fogelfors 2002; Kudsk i Streibig 2003).

Wśród niektórych autorów panuje przekonanie, iż obniżenie dawki stosowanych herbicydów może mieć wpływ na spadek plonu ziarna (Lipa 2004; Kwiatkowski i Wesołowski 2011). Uzyskane plony ziarna pszenicy ozimej z wszystkich kombinacji zabiegowych, uśrednione $\mathrm{z}$ trzech doświadczeń kształtowały się na poziomie od 5,38 do $6,17 \mathrm{t} / \mathrm{ha}$. W kombinacjach traktowanych herbicydem w wyższych testowanych dawkach uzyskano plony istotnie wyższe niż na obiekcie kontrolnym $(5,16 \mathrm{t} / \mathrm{ha})$. Średni plon ziarna na obiekcie $\mathrm{z}$ dawką obniżoną o $25 \%$ był najwyższy i wynosił 6,17 t/ha, a z dawką zredukowaną do 37,5\% $5,91 \mathrm{t} / \mathrm{ha}$. Wyjątek stanowiły kombinacje, w których zastosowano herbicyd w dawce obniżonej o 50 i $62,5 \%$

Tabela 1. Wpływ różnych dawek herbicydu Lancet Plus 125 WG z adiuwantem Olstick 90 EC na skuteczność zwalczania chwastów w pszenicy ozimej (średnia z sezonów 2010/2011 i 2012/2013)

Table 1. Efficacy of different doses of herbicide Lancet Plus 125 WG with adjuvant Olstick 90 EC in winter wheat (average for 2010/2011 and 2012/2013)

\begin{tabular}{|c|c|c|c|c|c|c|c|c|c|c|}
\hline \multirow[b]{2}{*}{$\begin{array}{c}\text { Kombinacja } \\
\text { Treatment }\end{array}$} & \multirow{2}{*}{$\begin{array}{c}\text { Dawka } \\
\text { Dose } \\
{[\mathrm{kg}, 1 / \mathrm{ha}]}\end{array}$} & \multirow{2}{*}{$\begin{array}{c}\text { Termin } \\
\text { zabiegu } \\
\text { Application } \\
\text { time }\end{array}$} & \multicolumn{8}{|c|}{ Średnie zniszczenie chwastów w \% - Average weed control in \% } \\
\hline & & & VIOAR & CENCY & PAPRH & BRSNW & MATIN & THLAR & GALAP & APESV \\
\hline $\begin{array}{l}\text { Kontrola - Untreated } \\
\left(\mathrm{szt} . \mathrm{m}^{2}-\mathrm{pcs} / \mathrm{m}^{2}\right)\end{array}$ & & - & $(35)$ & $(14)$ & $(11,5)$ & $(10)$ & $(9,3)$ & $(6,9)$ & $(2,5)$ & $(12)$ \\
\hline Lancet Plus 125 WG & 0,2 & $\mathrm{~T} 2$ & 98,7 & 98,3 & 100 & 100 & 98,3 & 100 & 100 & 100 \\
\hline $\begin{array}{l}\text { Lancet Plus } 125 \text { WG } \\
+ \text { Olstick } 90 \text { EC }\end{array}$ & $\begin{array}{c}0,2 \\
+1,0\end{array}$ & $\mathrm{~T} 2$ & 99,3 & 99,3 & 97,5 & 100 & 100 & 100 & 98,3 & 100 \\
\hline $\begin{array}{l}\text { Lancet Plus } 125 \text { WG } \\
+ \text { Olstick } 90 \text { EC }\end{array}$ & $\begin{array}{r}0,15 \\
+1,0 \\
\end{array}$ & $\mathrm{~T} 2$ & 98,3 & 97,8 & 94,0 & 100 & 98,3 & 100 & 98,3 & 100 \\
\hline $\begin{array}{l}\text { Lancet Plus } 125 \text { WG } \\
+ \text { Olstick } 90 \text { EC }\end{array}$ & $\begin{array}{l}0,125 \\
+1,0\end{array}$ & $\mathrm{~T} 2$ & 96,7 & 97,0 & 96,0 & 100 & 95,0 & 100 & 96,6 & 100 \\
\hline $\begin{array}{l}\text { Lancet Plus } 125 \text { WG } \\
+ \text { Olstick } 90 \text { EC }\end{array}$ & $\begin{array}{c}0,1 \\
+1,0 \\
\end{array}$ & $\mathrm{~T} 2$ & 89,3 & 90,5 & 94,4 & 89,0 & 89,0 & 90,0 & 91,6 & 93,3 \\
\hline $\begin{array}{l}\text { Lancet Plus } 125 \text { WG } \\
\text { + Olstick } 90 \mathrm{EC}\end{array}$ & $\begin{array}{r}0,075 \\
+1,0\end{array}$ & $\mathrm{~T} 2$ & 88,0 & 84,5 & 91,0 & 87,5 & 83,3 & 87,5 & 87,6 & 91,7 \\
\hline \multicolumn{3}{|l|}{$\mathrm{ED}_{90}[\mathrm{~g} / \mathrm{ha}]$} & 102,5 & 98,3 & 75,3 & 99,6 & 96,1 & 98,2 & 85,9 & 74,5 \\
\hline
\end{tabular}

Termin zabiegu - Application time:

T2 - w fazie krzewienia do początku strzelania w źdźbło pszenicy ozimej (BBCH 25-31) - full tillering stage until first node stage of winter wheat (BBCH 25-31)

VIOAR - Viola arvensis, CENCY - Centaurea cyanus, PAPRH - Papaver rhoeas, BRSNW - Brassica napus var. oleifera, MATIN - Matricaria inodora, THLAR - Thlaspi arvense, GALAP - Galium aparine, APESV - Apera spica-venti

$\mathrm{ED}_{90}[\mathrm{~g} / \mathrm{ha}]$ - wyliczono dla każdego gatunku chwastu, według działania różnych dawek herbicydu Lancet Plus 125 WG z adiuwantem Olstick 90 EC values were calculated for each weed species according to different doses of the herbicide Lancet 125 WG applied with adjuvant Olstick 90 EC 
Tabela 2. Wpływ zróżnicowanych dawek herbicydu Lancet Plus 125 WG z adiuwantem Olstick 90 EC na plon pszenicy ozimej (średnia z sezonów 2010/2011 i 2012/2013)

Table 2. The influence of various doses of herbicide Lancet Plus 125 WG with adjuvant Olstick 90 EC on the yield of winter wheat (average for 2010/2011 and 2012/2013)

\begin{tabular}{l|c|c|c|c|c}
\hline \multicolumn{1}{c|}{$\begin{array}{c}\text { Kombinacja } \\
\text { Treatment }\end{array}$} & $\begin{array}{c}\text { Dawka } \\
\text { Dose } \\
{[\mathrm{kg}, 1 / \mathrm{ha}]}\end{array}$ & $\begin{array}{c}\text { Termin } \\
\text { zabiegu } \\
\text { Application time }\end{array}$ & $\begin{array}{c}\text { MTZ } \\
\text { Weight } 1000 \text { grains } \\
{[\mathrm{g}]}\end{array}$ & $\begin{array}{c}\text { Gęstość ziarna } \\
\text { Grain density } \\
{[\mathrm{kg} / \mathrm{hl}]}\end{array}$ & $\begin{array}{c}\text { Plon } \\
\text { Yield } \\
{[\mathrm{t} / \mathrm{ha}]}\end{array}$ \\
\hline Kontrola - Untreated $\left(\mathrm{szt} . / \mathrm{m}^{2}-\mathrm{pcs} / \mathrm{m}^{2}\right)$ & & - & 42,4 & 71,05 & 5,16 \\
\hline Lancet Plus 125 WG & 0,2 & $\mathrm{~T} 2$ & 44,6 & 72,55 & 5,88 \\
\hline Lancet Plus 125 WG + Olstick 90 EC & $0,2+1,0$ & $\mathrm{~T} 2$ & 42,5 & 72,35 & 5,91 \\
\hline Lancet Plus 125 WG + Olstick 90 EC & $0,15+1,0$ & $\mathrm{~T} 2$ & 43,7 & 72,07 & 6,17 \\
\hline Lancet Plus 125 WG + Olstick 90 EC & $0,125+1,0$ & $\mathrm{~T} 2$ & 43,3 & 72,79 & 5,90 \\
\hline Lancet Plus 125 WG + Olstick 90 EC & $0,1+1,0$ & $\mathrm{~T} 2$ & 41,7 & 73,09 & 5,53 \\
\hline Lancet Plus 125 WG + Olstick 90 EC & $0,075+1,0$ & $\mathrm{~T} 2$ & 41,4 & 72,40 & 5,38 \\
\hline NIR (0,05) - LSD $(0.05)$ & & & r.n. & r. n. & 0,408 \\
\hline
\end{tabular}

Termin zabiegu - Application time:

$\mathrm{T} 2$ - w fazie krzewienia do początku strzelania w źdźbło pszenicy ozimej (BBCH 25-31) - full tillering stage until first node stage of winter wheat (BBCH 25-31)

r.n. - różnica nieistotna - not significant difference

(odpowiednio 5,53 i 5,38 t/ha). Plony te nie różniły się istotnie od plonu zebranego $\mathrm{z}$ obiektu kontrolnego. $\mathrm{Na}$ uwagę zasługuje również fakt, że plon uzyskany z kombinacji, w której stosowano pełną dawkę herbicydu wraz $\mathrm{z}$ adiuwantem był nieco wyższy od plonu ziarna pszenicy ozimej uzyskanego po zastosowaniu zalecanej dawki środka Lancet Plus $125 \mathrm{WG}(0,2 \mathrm{~kg} / \mathrm{ha})$ stosowanej bez wspomagacza.

Nie stwierdzono istotnych różnic w masie tysiąca ziaren (MTZ) i gęstości usypowej ziarna pszenicy zarówno pomiędzy obiektami traktowanymi herbicydem bez i z dodatkiem adiuwanta olejowego, jak i obiektami chronionymi a obiektem kontrolnym (bez odchwaszczania z użyciem herbicydu).

Jak wynika z podanych wyżej faktów, odpowiednie obniżenie dawki nie tylko nie wpłynęło na obniżenie plonu ziarna, a wręcz, w niektórych przypadkach wpłynęło na jego zwiększenie. Niebagatelne znaczenie ma tu z pewnością zastosowanie dodatku adiuwanta, zalecane przez wielu autorów w celu wyeliminowania lub minimalizo- wania ryzyka obniżenia plonu (Woźnica 2003; Kwiatkowski 2010).

Badania prowadzone w różnych ośrodkach badawczych (Domaradzki i Rola 2000; Krawczyk i Kaczmarek 2009; Paradowski i wsp. 2010; Miklaszewska i Kierzek 2013) potwierdzają stabilizację lub niekiedy zwyżkę plonów w wyniku zastosowania obniżonych dawek, w szczególności herbicydów wieloskładnikowych.

\section{Wnioski / Conclusions}

1. Wyniki badań wskazują na możliwość stosowania wieloskładnikowego herbicydu Lancet Plus 125 WG w obniżonych dawkach wraz z adiuwantem olejowym Olstick 90 EC w uprawie pszenicy ozimej.

2. W celu zachowania wysokiej skuteczności chwastobójczej i stabilnego plonu pszenicy ozimej najbardziej wskazane jest obniżanie dawki herbicydu Lancet Plus $125 \mathrm{WG}$, stosowanego z dodatkiem adiuwanta olejowego, w granicach od 25 do $50 \%$.

\section{Literatura / References}

Banaszkiewicz T. 1993. Zachowanie się herbicydów w roślinach. Fragm. Agron. 1: 72-81.

Bostrom U., Fogelfors H. 2002. Long-term effect of herbicide - application strategies on weeds and yield in spring - on cereals. Weed Sci. 50: 196-203.

Domaradzki K., Rola H. 2000. Efektywność stosowania niższych dawek herbicydów w zbożach. Pam. Puł. 120: 53-64.

Domaradzki K., Rola H. 2001. Ekologiczno-agronomiczne aspekty stosowania niższych dawek herbicydów w regulacji zachwaszczenia zbóż. [Elogical and agronomic aspects of application lower rates of herbicides in regulation of weed infestation in cereals]. Prog. Plant Prot./Post. Ochr. Roślin 41 (1): 229-239.

Domaradzki K., Sadowski J. 2002. Możliwość zmniejszenia obciążenia dla środowiska naturalnego poprzez stosowanie herbicydów w ograniczonych dawkach. Pam. Puł. 130: 99-114.

Domaradzki K., Rola H. 2003. The possibility of weed control in cereals by use low rates of herbicides - review of existing investigations. J. Plant Prot. Res. 43 (2): 163-170.

Domaradzki K., Praczyk T. 2004. Systemy wspierania decyzji w chemicznym zwalczaniu chwastów. [Decision suport systems in chemical weed control]. Prog. Plant Prot./Post. Ochr. Roślin 44 (1): 43-51. 
Domaradzki K., Kieloch R. 2005. Wpływ rodzaju adiuwanta oraz dawki mieszaniny jodosulfuronu i mezosulfuronu na skuteczność niszczenia Apera spica-venti, Alopecurus myosuroides i chwastów dwuliściennych. [Influence of adiuvant's kind and dose on efficacy of Apera spica-venti, Alopecurus myosuroides and broad-leaves weed control by jodosulfuron and mezosulfuron mixture]. Prog. Plant Prot./Post. Ochr. Roślin 45 (1): 91-99.

Haliniarz M., Kapeluszny J. 2012. Reakcja trzech odmian pszenicy jarej na zmniejszenie zalecanej dawki herbicydu Chwastox Trio 540 SL. Fragm. Agron. 29 (2): 33-42.

Holloway P.J., Butler Ellis M.C., Webb D.A., Western N.M., Tuck S.R., Hayes A.L., Miller P.C.H. 2000. Effects of some agricultural tank-mix adjuvants on the deposition efficiency of aqueous sprays on foliage. Crop Prot. 19: 27-37.

Kierzek R., Ratajkiewicz H. 2004. Wpływ adiuwantów i parametrów opryskiwania na retencję cieczy na liściach w wybranych roślinach jednoliściennych. [Effect of adjuvants and spray parameters on retention of liquids on selected monocotyledone foliage]. Prog. Plant Prot./Post. Ochr. Roślin 44 (2): 828-831.

Kraska P. 2007. Wpływ zróżnicowanych dawek herbicydów na plonowanie i zawartość makroelementów w ziarnie pszenicy ozimej. Biul. IHAR 246: 23-30.

Krawczyk R. 2007. Wpływ terminu stosowania zredukowanych dawek herbicydów w zbożach jarych na efektywność zwalczania chwastów. [Influence of application time of herbicide reduced doses on weed control efficiency In the spring cereals]. Prog. Plant Prot./Post. Ochr. Roślin 47 (3): 151-158.

Krawczyk R., Kaczmarek S. 2009. Possibilities of weed control in spring cereals using small herbicide doses in Poland conditions. J. Centr. Europ. Agric. 10: 433-438.

Kudsk P., Streibig J.V. 2003. Herbicides - a two-edged sword. Weed Res. 43: 90-102.

Kudsk P. 2008. Optimising herbicide dose: a straightforward approach to reduce the risk of side effects of herbicides. Environmentalist 28: 49-55.

Kwiatkowski C. 2010. Wpływ adiuwantów oraz zredukowanych dawek środków ochrony roślin na wskaźniki jakości technologicznej ziarna pszenicy ozimej. [Effect of adjuvants and reduced doses of pesticides on technological quality indices of winter wheat grain]. Prog. Plant Prot./Post. Ochr. Roślin 50 (2): 994-998.

Kwiatkowski C.A., Wesołowski M. 2011. Wpływ adiuwantów oraz zredukowanych dawek środków ochrony roślin na zachwaszczenie pszenicy ozimej. [Effect of adjuvants and reduced doses of pesticides on weed infestation in winter wheat]. Prog. Plant Prot./Post. Ochr. Roślin 51 (1): 348-353.

Lipa J.J. 2004. Nowoczesna ochrona zbóż. Pam. Puł. 135: 241-259.

Miklaszewska K., Kierzek R. 2013. Skuteczność chwastobójcza obniżonych dawek preparatów Dragon 450 WG i Granstar Ultra SX 50 SG w uprawie jęczmienia jarego. [Response of weeds to different doses of Dragon 450 WG and Granstar Ultra SX 50 SG in spring barley]. Prog. Plant Prot./Post. Ochr. Roślin 53 (1): 91-95.

Paradowski A., Pietryga J., Matysiak K. 2010. Optymalizacja dawek herbicydów w pszenicy jarej i jęczmieniu jarym. [Weed management in spring cereals]. Prog. Plant Prot./Post. Ochr. Roślin 50 (4): 1859-1868.

Praczyk T., Bączkowska E., Balcer G., Kulczyński J., Dorna J. 2008. Nowy adiuwant wspomagający aktywność niektórych herbicydów i fungicydów. [New adjuvant improving activity of some herbicides and fungicides]. Prog. Plant Prot./Post.Ochr. Roślin 48 (2): $646-652$.

Roberson J.L., Preisler H.K., Russell R.M. 2002. Polo Plus. Probit and Logit Analysis. User's Guide. LeOra Software, Petaluma, CA, USA, $36 \mathrm{pp}$.

Talgre L., Lauringson E., Koppel M., Nurmekvi H., Sulev U. 2004. Weed control in spring barley by lower doses in Estonia. Agronomijas Vestis LLU 7: 171-175.

Wesołowski M., Cierpiała R. 2010. Plonowanie i zachwaszczenie pszenicy ozimej w zależności od dawek herbicydu Huzar 05 WG. Acta Agrophys. 15 (2): 429-439.

Woźnica Z. 2008. Herbologia. Podstawy biologii, ekologii i zwalczania chwastów. PWRiL, Poznań, 430 ss. 